\title{
A RARE AND ATYPICAL MULLERIAN ANOMALY WITH DUPLICATION AND AGENESIS WITHOUT ANY PRESENT CLASSIFICATION
}

\author{
Punit Hans ${ }^{1}$, Valya Agarwal2 ${ }^{2}$ Kalpana Kumari ${ }^{3}$
}

\section{HOW TO CITE THIS ARTICLE:}

Punit Hans, Valya Agarwal, Kalpana Kumari. "A Rare and Atypical Mullerian Anomaly with Duplication and Agenesis without Any Present Classification". Journal of Evolution of Medical and Dental Sciences 2014; Vol. 3, Issue 57, October 30; Page: 13040-13042, DOI: 10.14260/jemds/2014/3731

ABSTRACT: A 29 year old unmarried woman with primary amenorrhea consulted her doctor. On further questioning the patient complained of monthly cyclical severe pain abdomen for 2-3 days which was relieved only after administration of injectable pain killers like tramadol. She also gave history of vaginoplasty done 8 years back. On examination the patient was of thin built and her secondary sexual characters were well developed. Her per abdominal examination was normal. On per vaginal examination cervix and uterus was not felt and vaginal length was $3 \mathrm{~cm}$. On per rectal examination also uterus was not felt. She was sent for ultrasound examination that showed two separate uteri with fundus and body but no cervix, both ovaries were present. After routine work up and investigations patient was put up for laparotomy, right sided hysterectomy with salpingooophorectomy and left sided hysterectomy with removal of fallopian tube done while left ovary was preserved. Thus, a rarest anomaly of mullerian system was reveled and managed leading to freedom of patient of her monthly cyclical severe abdominal pain.

KEYWORDS: Mullerian anomalies, cervical agenesis.

INTRODUCTION: Congenital anomalies of the Müllerian system are rare occurences. The prevalence of these anomalies ranges from 0.001 to $10 \%$ in the general population and from $8-10 \%$ in women with an adverse reproductive history.[1,2] The case described here is a mullerian duct anomaly with two separate uterus hanging from lateral pelvic wall each with fundus and body but no cervix while two adhered ovaries were present.As this is a rare atypical anomaly not much review of literature was available for it,so efforts have been made by us to report this rare case.

CASE REPORT: A 21 year old unmarried woman presented with primary amenorrhoea and severe monthly cyclical pain in lower abdomen of 2-3 days duration that was relieved only after using injectable analgesics like tramadol, diclofenac etc.On further questioning she gave history of vaginoplasty done in 2006 and a laparoscopy done in 2011. According to laproscopy reports uterus without cervix in two halves hanging from both pelvic wall was seen and ovaries were polycystic.

On examination she was thin, afebrile with blood pressure 105/66mmHg,pulse rate $89 /$ minute. She was having slight pallor but no edema,no clubbing, no cyanosis, no icterus. On chest auscultation normal bronchial and vesicular sounds heard,both heart sounds were normal with no murmurs. Nothing relevant found on palpation of her abdomen. During per vaginal examination vulva was found healthy,vaginal length was about $3 \mathrm{~cm}$ niether cervix nor uterus was felt.

On per rectal examination no uterus was felt. She was admitted and adviced for ultrasound scan of whole abdomen with special emphasis on genitourinary structures. The patient's ultrasound report of 3 August 2014 showed bilateral normaly placed normal sized kidneys with normal parenchymal echotexture, collecting duct system not dilated, right kidney measured $9.3 \mathrm{~cm}$, left 
kidney measured $9.6 \mathrm{~cm}$, normal urinary bladder wall. Two separate uterus having fundus body and absent cervix, deviated towards left and right side with adhered ovaries were seen. Right sided uterus measured $2.0 \times 3.2 \mathrm{~cm}$ with endometrial thickness of $3.0 \mathrm{~mm}$. Left sided uterus measured $2.2 \times 8 \mathrm{~cm}$ with endometrial thickness of $3.9 \mathrm{~mm}$. The right ovary measured $1.8 \times 1.7 \mathrm{~cm}$, volume $2.8 \mathrm{ml}$. Left ovary measured $1.9 \times 1.2 \mathrm{~cm}$, volume $1.5 \mathrm{ml}$.

According to laboratory reports on 29 August 2014 her hemoglobin was $11.5 \mathrm{gm} / \mathrm{dl}$, total wbc count was $8900 / \mathrm{Cu} \mathrm{mm}$, platelet count was $2.10 \mathrm{Lacs} / \mathrm{Cu} \mathrm{mm}$, differential wbc count was- neutrophil $58 \%$, lymphocytes $36 \%$, monocytes $01 \%$, eosinophils $05 \%$, basophils $00 \%$. Her blood group was $\mathrm{AB}$ Positive, bleeding time by Duke's method was 20 seconds, clotting time by capillary method was 2 minute 20 seconds. Her blood sugar[fasting] was $105.0 \mathrm{mg} / \mathrm{dl}$, serum creatinine $1.1 \mathrm{mg} / \mathrm{dl}$, total bilirubin $0.8 \mathrm{mg} / \mathrm{dl}$, Serum SGPT $35.8 \mathrm{IU} / \mathrm{L}$, Blood urea 25,8 mg/dl, direct bilirubin $0.1 \mathrm{mg} / \mathrm{dl}$.

She was negative for HIV,HbsAG, HCV Tests.Her routine urine examination was normal and culture sensitivity of urine showed no growth. ECG and Chest Xray PA view were normal. After all work up and investigations, the patient was counselled for her future married life and infertility. A exploratory laprotomy done under spinal anaesthesia. An infraumbilical midline longitudinal incision was given rectus seath and peritoneum oppened. There were two small uterus, right 1.5"and left about 1" hanging from lateral pelvic walls (Fig.1 \& Fig.2). Both uterus were having fundus and body but were devoid of cervix.

Round ligament of both sides were ligated and cut,bladder was dissected down. Right sided hysterectomy with salpingoophorec-tomy and left sided hysterectomy with removal of left fallopian tube done. Left ovary was preserved to save the patient from early menopausal symptoms and other complications. Hemostasis secured and abdomen closed in layers after counting tetrads and instruments. Decision of removal of both uterus was taken as previous datas and statistics support the fact that patients with a confirmed diagnosis of cervical agenesis should be referred for hysterectomy. Several surgical attempts to create a cervix have resulted in tragic outcomes, often associated with fatal complications.[3]

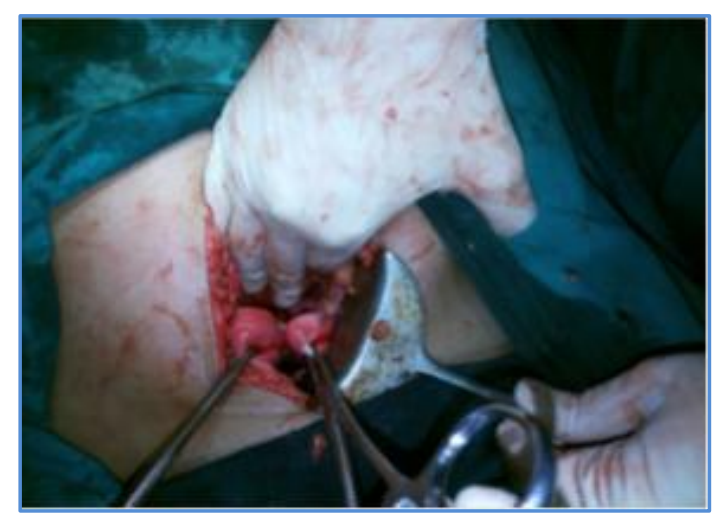

Fig. 1: Two separate uterus hanging from lateral pelvic walls

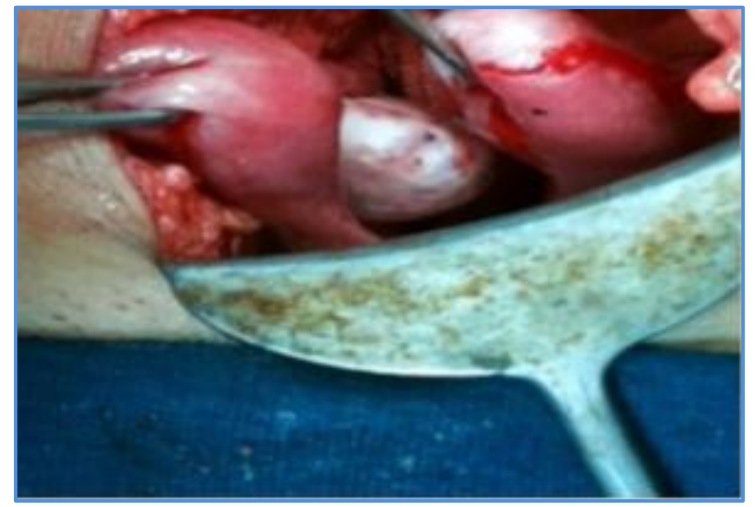

Fig. 2: The two uterus with fundus and body

DISCUSSION: It is theorized that the mullerian ducts fuse around the eleventh through the thirteenth weeks in utero and that fusion and absorption are unidirectional from caudal to cephalad. Our current classification system for uterine anomalies is based on this unidirectional theory. In our this rare 
atypical case there might be failure of both development and fusion of mullerian ducts that resulted in two separate uterus without cervix.As this was the rarest case not much explanation could be found about this anomaly from the avialable literatures.

Müllerian anomalies consist of a wide range of rare defects that may vary from patient to patient. Therefore, their management must also be individual, taking anatomical and clinical characteristics into consideration, as well as the patient's wishes. The prospects for pregnancy using in vitro fertilization techniques should be evaluated in the light of the obstetrical complications, and possible alternatives should be offered to these women. The use of a surrogate womb may be the best option in our case.

\section{REFERENCES:}

1. Pui MH. Imaging diagnosis of congenital uterine malformation. Comput Med Imaging Graph. 2004; 28 (7): 425-33.

2. Propst AM, Hill JA 3rd. Anatomic factors associated with recurrent pregnancy loss. Semin Reprod Med. 2000; 18 (4): 341-50.

3. Acién P. Reproductive performance of women with uterine malformations. Hum Reprod. 1993; 8 (1): 122-6.

\section{AUTHORS:}

1. Punit Hans

2. Valya Agarwal

3. Kalpana Kumari

\section{PARTICULARS OF CONTRIBUTORS:}

1. Junior Resident, Department of Obstetrics and gynaecology, NMCH, Patna.

2. Senior Resident, Department of Obstetrics and gynaecology, NMCH, Patna.

3. Junior Resident, Department of Obstetrics and gynaecology, NMCH, Patna.

\author{
NAME ADDRESS EMAIL ID OF THE \\ CORRESPONDING AUTHOR: \\ Punit Hans Niketan, \\ Mukhopadhya Colony, \\ Opp. Bazar Samiti Main Gate, \\ PO-Mahendru, \\ Patna-800006, Bihar. \\ Email: punit.1628@gmail.com
}

Date of Submission: 09/10/2014. Date of Peer Review: 10/10/2014. Date of Acceptance: 27/10/2014. Date of Publishing: 30/10/2014. 